\title{
Estratégia\&Negócios
}

ISSN 1984-3372

http://www.portaldeperiodicos.unisul.br/index.php/EeN/

PERFIL DA PRODUÇÃO CIENTÍFICA BRASILEIRA SOBRE BALANCED SCORECARD

PROFILE OF BRAZILIAN SCIENTIFIC PRODUCTION ABOUT BALANCED SCORECARD

\section{Fabiano Ferreira}

Mestrando em Ciências Contábeis pela Universidade do Vale do Rio dos Sinos - Unisinos.

E-mail: fabianoferreira987@hotmail.com

\section{Carlos Alberto Diehl}

Professor Titular do PPG em Ciências Contábeis da Universidade do Vale do Rio dos Sinos - Unisinos,

E-mail: $\underline{\text { cd@unisinos.br }}$

Recebido em 04/12/2012. Aprovado em 03/02/2013. Disponibilizado em 05/05/2013.

Avaliado pelo Sistema double blind review

R. eletr. estrat. neg., Florianópolis, v.6, n.1, p.54-88, jan./abr. 2013

http://portaldeperiodicos.unisul.br/index.php/EeN/index
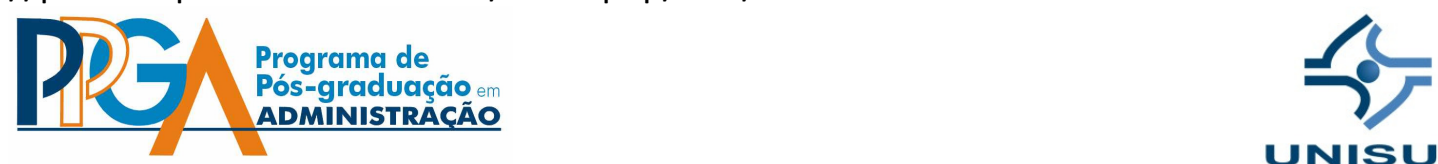

UNISUL

(C) Copyright 2008 UNISUL-PPGA/Estratégia e Negócios. Todos os direitos reservados. Permitida citação parcial, desde que identificada a fonte. Proibida a reprodução total. Em caso de dúvidas, consulte o editor: ademar.unisul@gmail.com; (48) 3229-1932. 
RESUMO

Este estudo tem por objetivo apresentar e analisar o perfil das publicações científicas sobre o sistema de avaliação de desempenho Balanced Scorecard (BSC), disponibilizadas na base de dados SciELO Brasil e na Biblioteca Digital Brasileira de Teses e Dissertações (BDTD). Trata-se de um estudo quantitativo, e para o seu desenvolvimento foram realizadas pesquisas bibliográficas e análise bibliométrica. Por meio dessa investigação, identificaram-se os objetivos dos estudos, a quantidade de trabalhos disponíveis nas bases de dados, o vínculo institucional dos autores, o ano de publicação ou defesa dos trabalhos desenvolvidos, bem como a metodologia utilizada pelos pesquisadores e a produção científica de cada estado. Especificamente na base de dados da Scielo Brasil, foi possível identificar, ainda, os autores e as revistas que publicaram os artigos. O trabalho revelou, entre outros aspectos, que as publicações sobre o BSC demonstram uma grande variedade de objetivos e que os pesquisadores tendem a utilizar filosofia do Balanced Scorecard não só em empresas com fins lucrativos, mas também na administração pública e em empresas do terceiro setor, bem como no ramo agropecuário. Os estudos sobre o BSC no Brasil iniciaram no ano de 2000. Dois autores por artigo é a combinação que mais se repete nas publicações na base SciELO Brasil. Quanto à localização geográfica os Estados que mais contribuíram, verificou-se participação do Rio Grande do Sul, de São Paulo, do Rio de Janeiro e de Pernambuco.

Palavras-chave: avaliação de desempenho. Balanced Scorecard. Bibliometria.

\section{INTRODUÇÃO}

O atual ambiente de negócios em que as empresas estão inseridas, caracterizado pelo alto grau de competitividade, faz com que elas ajustem suas estruturas, suas estratégias, seus processos internos e sua maneira de gestão, tanto para atender às expectativas de seus clientes quanto para oferecer aos acionistas o retorno esperado sobre seus investimentos. Diante disso, o desenvolvimento de produtos ocorre de forma cada vez mais acelerada, e fatores como qualidade, preço e 
prazo de entrega têm feito as empresas aperfeiçoarem o gerenciamento de seus negócios a curto e a longo prazo (BERTUCCl; HIRSCHHEIMER, 2005).

Esse cenário empresarial aumentou o nível de exigência sobre a forma de gestão, de modo que as organizações que pretendem manter seus estilos de competitividade devem estar em um contínuo processo de melhoria das suas ações. Diehl e Cardoso (2011) destacam que para a empresa obter e manter os melhores resultados econômicos, de forma que satisfaça todas as partes relacionadas, ou seja, de forma sustentável, é necessário identificar como se chega ao resultado e, principalmente, como se o mantém, levando, então, à necessidade de análise do desempenho. Assim, as medidas tradicionais de avaliação de desempenho baseadas em indicadores financeiros não suportam o nível de informação requerido diante do atual panorama empresarial, cabendo a incorporação de indicadores não financeiros para o auxílio no controle gerencial e na implantação de novas estratégias.

Diante da necessidade de uma avaliação de desempenho adequada para o atual cenário de negócios, surgiram vários modelos de avaliação de desempenho, a fim de auxiliar os gestores na tomada de decisão, nos controles empresariais e no planejamento e execução da estratégia. Como exemplo, pode-se citar o modelo de avaliação de desempenho desenvolvido por Sink e Tuttle (1993), chamado de "Sete critérios de avaliação de desempenho", ou tableau de bord, e o Balanced Scorecard, apresentado por Kaplan e Norton em 1992. Para Prieto et al. (2006, p. 81) "os métodos atualmente mais referenciados são o Balanced Scorecard (BSC) [...], a Pirâmide de Desempenho - Performance Pyramide [...] e o Prisma de Desempenho - Performance Prism [...], dentre os quais o BSC tem se tornado o mais difundido nas empresas".

O Balanced Scorecard, como defende Prieto et al. (2006) e Assiri, Zairi e Eid (2006), tornou-se um dos métodos mais difundidos nas empresas e isso levou diversos pesquisadores a desenvolverem trabalhos que abordassem esse tema. Os estudos desenvolvidos no meio acadêmico procuram resolver ou auxiliar na resolução dos problemas que se apresentam nas organizações e na sociedade. Para Vanti (2002), uma das técnicas de se avaliar os estudos é por meio da bibliometria, que tem como objetivo estudar as publicações científicas sobre determinado tema, revelando como o saber vem se desenvolvendo e como está contribuindo para resolver tais problemas. 
Dessa forma, surgiu o problema dessa pesquisa, que pode ser expresso da seguinte forma: como as publicações científicas sobre o BSC tratam o tema no Brasil? Ou seja, é importante verificar o perfil das publicações sobre o Balanced Scorecard, quem são os autores, quais os métodos de pesquisa utilizados, qual o objetivo das pesquisas envolvendo o BSC, quais os periódicos que publicaram sobre o tema etc.

Destaca-se que o perfil esperado é que haja uma produção científica, compatível com o que está se desenvolvendo na prática empresarial, ou seja, se o BSC é considerado um dos métodos de avaliação de desempenho mais difundido no meio empresarial, logo, sua presença possivelmente também deverá ser representativo nos estudos e publicações. Diante disso, este trabalho visa a apresentar e analisar o perfil das publicações científicas sobre o Balanced Scorecard, disponibilizadas na base de dados SciELO Brasil e na Biblioteca Digital Brasileira de Teses e Dissertações.

Trata-se de um estudo quantitativo e para o seu desenvolvimento foram realizadas pesquisas bibliográficas e análise bibliométrica. O estudo possibilitará avaliar e refletir sobre esses trabalhos e sobre o tema em questão. Para Cardoso et al. (2005, p. 35), "tal análise permite detectar indicadores, tendências e vieses de cada área. As revisões são em geral feitas por técnicas tradicionais no meio acadêmico, como a análise bibliométrica".

Este artigo contém, além dessa introdução, a seção 2, onde será apresentada a revisão da literatura, que está conectada ao objeto de estudo e contempla as definições sobre o BSC, seus propósitos como sistema de mensuração de desempenho, seus componentes, suas perspectivas de ação, dando ênfase aos benefícios e às críticas apresentadas ao Balanced Scorecard e também sobre a bibliometria. Na seção 3, será destacada a metodologia utilizada na elaboração desta pesquisa. Na seção seguinte (4), serão apresentados e analisados os dados, e, por fim, na seção 5, serão apresentadas as considerações finais. 


\section{REVISÃO DA LITERATURA}

\subsection{DEFINIÇÕES SOBRE O BALANCED SCORECARD}

Em 1992, Kaplan e Norton já destacavam que os executivos compreendiam que as tradicionais medidas financeiras de contabilidade podem dar sinais enganosos sobre a melhoria contínua e a inovação que as demandas dos dias de hoje exigem. Nesse sentido, muitas críticas surgiram aos mecanismos de avaliação e monitoramento de desempenho econômico e de gestores, baseados exclusivamente em métricas financeiras, como Economic Value Added (EVA) e o Value-Based Management (VBM), no sentido principalmente de que estes se concentram na visão de curto prazo, evidenciando o foco de maximização do valor ao acionista, predominante na cultura norte-americana (DIETSCHI; NASCIMENTO, 2008). Os gestores com remuneração variável atrelada unicamente aos indicadores financeiros e ao valor acionário podem buscar a não investir (ou desinvestir) em projetos de pesquisa promissores, a fim de melhorar a lucratividade divulgada na publicação das demonstrações contábeis trimestrais de uma corporação (DIETSCHI; NASCIMENTO, 2008).

O surgimento do BSC, segundo Lima, Cavalcante e Ponte (2004), está relacionado com a necessidade de orientações adequadas para a tomada de decisões, com vistas a agregar valor à empresa, o que não é possível se ter com base nos indicadores financeiros, que só analisam o passado. Frezatti (2009) manifesta-se observando que a complexidade das operações e a necessidade de alinhamento entre o plano estratégico e o tático das organizações fizeram com que o BSC fosse proposto como complemento ao processo de planejamento e como sistema de alinhamento e gestão da estratégia.

A fragilidade nos sistemas de mensuração e de controle financeiro, segundo Atkinson et al. (2008), é remediada com a utilização do BSC, que acrescenta outras três perspectivas: a do cliente, a dos processos e a da aprendizagem e do crescimento. Para Gassenferth e Soares (2007), os indicadores e as práticas de controle financeiro não cederam espaço às perspectivas não financeiras do BSC, mas se integraram a essa ferramenta em uma espécie de associação, resultante, 
possivelmente, do modelo econômico e tecnológico em que as organizações estão inseridas, estando os empresários com cada vez mais controle das despesas operacionais e de capital.

Foi nesse contexto de críticas que Kaplan e Norton (1992) apresentaram o BSC, conceituado, na época, como um conjunto de medidas que proporciona à alta gerência uma visão rápida e abrangente do negócio, incluindo medidas financeiras que demonstram os resultados das ações já tomadas e complementando com medidas operacionais de satisfação do cliente, processos internos e de inovação da organização e melhorias das medidas das atividades operacionais.

Conceitos mais recentes sobre o BSC são abordados, por exemplo, em Lemos et al. (2011), que destaca que o BSC é usado como um sistema de gestão estratégica. Entendimento semelhante tem Chavan (2009), ao destacar que o BSC auxilia a esclarecer e traduzir a visão da empresa em estratégia, bem como comunica os objetivos estratégicos e as medidas planejadas, ajuda a estabelecer metas e alinhar iniciativas estratégicas, melhora o feedback estratégico e de aprendizagem. Sobre este último aspecto, Kaplan e Norton (2000) citam os cinco princípios de uma organização orientada à estratégia que são: a) o Princípio 1 - Mobilização da liderança executiva -, que pressupõe envolvimento ativo da liderança; b) o Princípio 2 - Tradução da estratégia em termos operacionais -, considerado um pré-requisito para a implantação dos demais; c) o Princípio 3 - Alinhamento organizacional -, que trata do alinhamento da estratégia da empresa por toda a organização; d) o Princípio 4 - Transformar a estratégia em tarefa de todos -, que prioriza a comunicação da estratégia a toda a organização; e, e) o Princípio 5 - Estratégia com processo contínuo -, que pressupõe análise e discussões periódicas sobre a estratégia da empresa.

\subsection{OBJETIVOS E COMPONENTES DO BSC}

O propósito inicial do BSC, destacado por Frezatti (2009), era ampliar o alcance das medidas de desempenho, de forma a dispor de um conjunto de medidas adequadas ao acompanhamento da implementação e execução da estratégia delineada pelas empresas. Na opinião de Valmohammadi e Servati (2011), o Balanced 
Scorecard fornece um quadro abrangente que traduz os objetivos estratégicos de uma empresa em um conjunto coerente de medidas de desempenho. A maior força do Balanced Scorecard, em comparação com outros sistemas, reside na sua capacidade de vincular desempenho entre diferentes classes de negócio desempenho - financeiros e não financeiros, internos e externos.

Com o objetivo de descrever e implementar a estratégia, Kaplan e Norton (2001) desenvolveram o mapa estratégico. Eles o conceituaram como uma arquitetura lógica e abrangente que serve para descrever a estratégia. Para Banker, Chang e Pizzini (2011), o mapa estratégico é um mapa causal que descreve as relações entre várias medidas de desempenho e objetivos corporativos. Para estes autores, os mapas causais expressam a opinião de que certos eventos ou ações levarão a resultados estratégicos específicos.

Um mapa estratégico especifica os elementos críticos e suas ligações para a estratégia de uma organização, levando em consideração: a) os objetivos para o crescimento e produtividade para aumentar o valor para os acionistas; b) o mercado, a aquisição e retenção de clientes-alvo, onde o crescimento rentável irá ocorrer; c) propostas de valor que iriam levar os clientes a fazerem mais negócios de maior margem com a empresa; d) inovação e excelência em produtos, serviços e processos que entregam a proposta de valor para segmentos específicos de clientes, promovendo melhorias operacionais, e conhecendo as expectativas da comunidade e os requisitos regulamentares; e) investimentos necessários em pessoas e sistemas para gerar e sustentar o crescimento (KAPLAN; NORTON, 2001).

Kaplan e Norton (2001) esclarecem que o mapa estratégico ocorre de cima para baixo, ou seja, as ações partem da visão e dos valores da empresa definidos pela alta gerência até se desdobrarem e chegarem à produção. Os mapas ajudam a mostrar para os empregados quais são as perspectivas da empresa, por isso as medidas de desempenho dispostas nas quatro perspectivas (financeira, dos clientes, negócios internos, aprendizado e crescimento) facilitam o dimensionamento do valor dos ativos intangíveis ao ligá-los à estratégia. 


\subsection{PERSPECTIVAS NO BSC}

Kaplan e Norton (1992) trazem a representação equilibrada de medidas financeiras e não financeiras organizadas em quatro perspectivas básicas, fornecendo respostas para as questões: a) como os clientes nos veem?; b) Em que devemos ser excelentes? c) Podemos inovar e criar valor? d) Como nós olhamos para os acionistas? As perspectivas na visão de Kaplan e Norton (1992) serão apresentadas no Quadro 1, a seguir:

Quadro 1 - Caracterização das quatro perspectivas

\begin{tabular}{|c|c|}
\hline Perspectivas & Características \\
\hline Financeira & $\begin{array}{l}\text { Medidas de desempenho financeiro indicam se a implementação e execução da } \\
\text { estratégia da empresa está contribuindo para a melhoria dos resultados finais. Entre as } \\
\text { medidas, destaca-se o fluxo de caixa, o crescimento das vendas, o lucro operacional } \\
\text { trimestral e a prosperidade em participação de mercado }\end{array}$ \\
\hline Do cliente & $\begin{array}{l}\text { O Balanced Scorecard exige que os gerentes desdobrem a missão geral no atendimento } \\
\text { ao cliente em medidas específicas, que reflitam os fatores que realmente importam } \\
\text { para os clientes. Eles destacam que as preocupações dos clientes tendem a cair em } \\
\text { quatro categorias: tempo, qualidade, desempenho e serviço e custo. Para essas } \\
\text { categorias, deve-se ter objetivos e medidas. }\end{array}$ \\
\hline $\begin{array}{l}\text { Dos } \\
\text { processos } \\
\text { internos }\end{array}$ & $\begin{array}{l}\text { Medidas com base nos clientes são importantes, mas devem ser traduzidos em medidas } \\
\text { do que a empresa deve fazer internamente para atender às expectativas de seus } \\
\text { clientes. Afinal, a satisfação excelente do cliente deriva de processos, decisões e ações, } \\
\text { que ocorrem em toda a organização. Os gerentes precisam concentrar-se nas operações } \\
\text { críticas internas que lhes permitem satisfazer as necessidades dos clientes. }\end{array}$ \\
\hline $\begin{array}{l}\text { De } \\
\text { aprendizagem } \\
\text { e crescimento }\end{array}$ & $\begin{array}{l}\text { No atual ambiente em que as empresas estão inseridas, há necessidade de melhorias } \\
\text { contínuas em seus produtos e processos. Isso serve para ter a capacidade de introduzir } \\
\text { produtos totalmente novos com capacidades expandidas. A capacidade de uma } \\
\text { empresa para inovar, melhorar e aprender está diretamente ligada ao seu valor, isto é, } \\
\text { somente por meio da capacidade de lançar novos produtos, criar mais valor para os } \\
\text { clientes, melhorar a eficiência operacional continuamente é que a empresa pode } \\
\text { penetrar em novos mercados e aumentar as receitas e margens e, consequentemente, } \\
\text { aumentar o valor para o acionista. }\end{array}$ \\
\hline
\end{tabular}

Fonte: Baseado em Kaplan e Norton (1992).

Apesar de o Balanced Scorecard servir-se das quatro perspectivas, Vila, Costa e Rovira (2010), destacam que, na prática, as perspectivas podem ser adaptadas a situações específicas de cada empresa, observando-se o contexto organizacional, o ramo de atividade e as peculiaridades de cada instituição.

No inicio da década de 90, o BSC era mais voltado para a mensuração de desempenho e para controle, mas este passou a ser utilizado, no atual cenário econômico, como uma ferramenta de desdobramento do planejamento estratégico da empresa. Isso pode ser observado na Figura 1, que apresenta as tabelas divulgadas por Kaplan e Norton em 1992 e em 2007. 
Figura 1 - Comparação das tabelas entre a primeira divulgação do BSC de Kaplan e Norton em 1992 e a divulgação em 2007

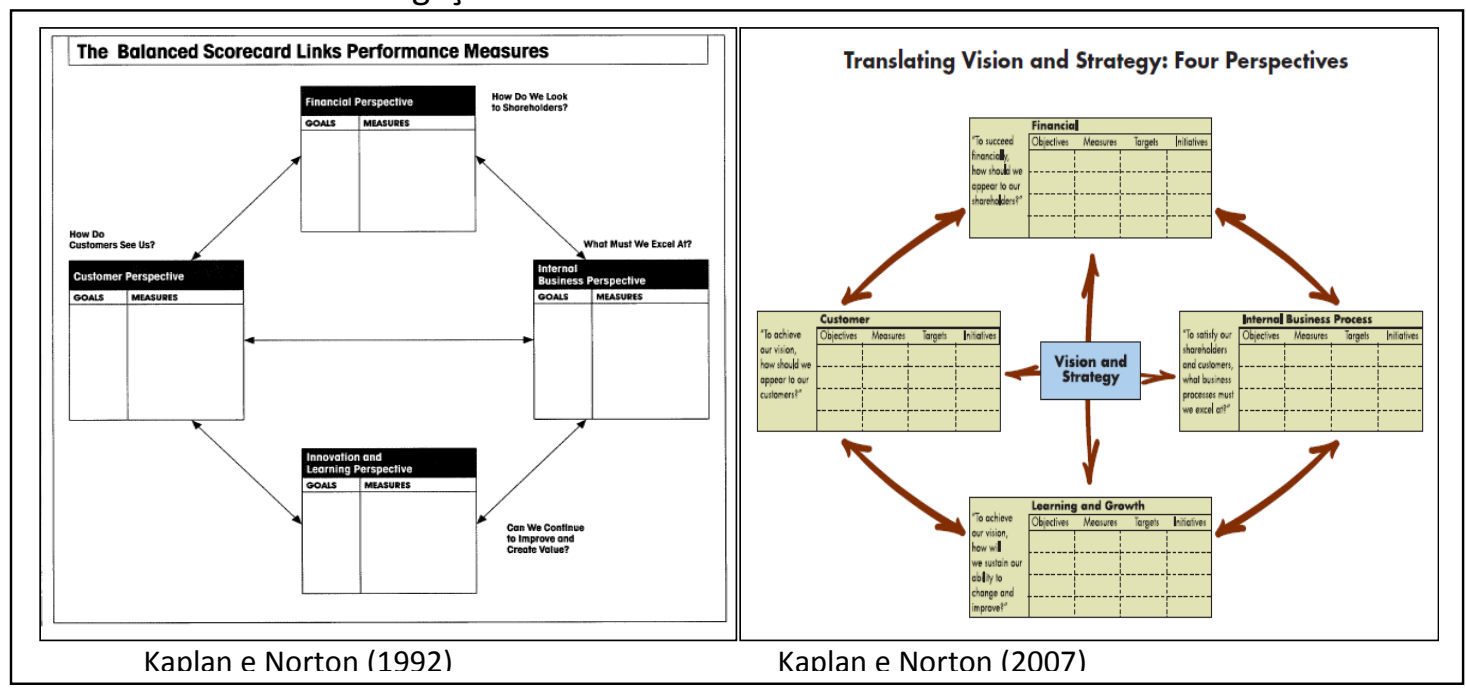

Fonte: Kaplan e Norton (1992- 2007).

Observa-se que na primeira figura, as perspectivas eram divididas em duas colunas: objetivos e medidas, demonstrando a sua utilização como medida de desempenho. Já na segunda, elas eram divididas em quatro colunas: objetivos, medidas, metas e iniciativas. Isso demonstra a sua proposta de utilização para fins estratégicos, estabelecendo metas e iniciativas. Para Dietschi e Nascimento (2008), o conceito do BSC, no primeiro artigo publicado por Kaplan e Norton, em 1992, era mais rudimentar do que os conceitos atuais. Dietschi e Nascimento (2008) esclarecem que apenas com a publicação do primeiro livro, em 1996, é que os autores introduziram o conceito de causa e efeito, e que o conceito de mapa estratégico surgiu com a publicação do segundo livro.

Em 2007, em seu artigo, Kaplan e Norton (2007) destacam que o BSC permite introduzir quatro novos processos de gestão que, separadamente ou em combinação, contribuem para vincular, em longo prazo, os objetivos estratégicos com ações de curto prazo. Os quatro novos processos têm por objetivo traduzir a visão estratégica, comunicar e vincular, planejar o negócio, e retorno e aprendizado.

\subsection{BENEFÍCIOS DO BSC}


Além dos benefícios explicitados pelos seus idealizadores como um sistema de mensuração de desempenho e também como um desdobramento das estratégias das empresas, outros benefícios podem ser destacados. Por exemplo, Assiri, Zairi e Eid (2006) destacam que um benefício potencial do BSC é a implementação de um sistema claro de relatórios periódicos. O BSC tornou-se um método popular de informação comumente praticado nos últimos anos. O BSC também pode habilitar as organizações a integrarem todos os aspectos do sistema de gestão da informação, e pode ter uma consequência de como gerentes pensam sobre seus negócios e como eles investem o seu tempo e recursos (ASSIRI; ZAIRI; EID, 2006).

O BSC pode ajudar a resolver vários problemas e fornecer à organização o planejamento de ações. Assiri, Zairi e Eid (2006) destacam que as medidas de Balanced Scorecard podem ajudar na solução dos problemas de comunicação de processos das equipes de várias maneiras, incluindo o desenvolvimento de uma compreensão comum do problema, o que significa que uma solução foi encontrada, além de testar possíveis soluções. Segundo eles, o BSC permite à organização focar seus esforços nesses processos críticos.

Lopes (2011) desenvolveu um estudo na Degrémont Tatamento de Águas LTDA., no qual concluiu que o BSC pode constituir uma ferramenta gerencial que traz reflexos positivos, tanto financeiros como não financeiros. Sob o aspecto financeiro, a empresa aumentou o faturamento e diminuiu os custos e despesas. Do ponto de vista não financeiro, teve-se uma melhora na cultura organizacional, com o comprometimento dos funcionários e melhor a comunicação da estratégia da empresa.

Sob o ponto de vista de Letza (1996) com a implantação efetiva do BSC, é possível a) fornecer informações que formam a espinha dorsal da estratégia de uma organização; b) funcionar como uma base do sucesso atual e futuro de uma organização, por equilibrar desempenho de curto prazo, essencialmente financeiro, com crescimento de oportunidades de longo prazo; c) destacar o desempenho, ligando os resultados financeiros ou serviços com o cliente e interfaces de mercado e motivação dos funcionários; d) atuar como uma ferramenta de integração, tanto horizontalmente (entre funcionalidade) como verticalmente (por meio de níveis de 
gestão), comunicando as prioridades de uma organização e estratégia de negócios; e e) servir como um processo dinâmico e contínuo de avaliação de desempenho, redefinindo a estratégia baseada em resultados.

O estudo feito por Lima, Cavalcante e Ponte (2004) revelou que é possível integrar a Gestão da Qualidade Total ao Balanced Scorecard, pois os dois modelos apresentam uma complementaridade entre eles. O BSC é efetivamente um modelo mais amplo e completo, que consegue abranger as medidas utilizadas com a dimensão da qualidade, e agregar medidas estratégicas. Sendo assim, a utilização conjunta dos modelos permite à empresa gerenciar seus indicadores de qualidade, na forma proposta pela Gestão da Qualidade Total, alinhando-os aos seus objetivos estratégicos.

\subsection{CRÍTICAS AO BSC}

A prática do BSC em empresas da chamada "economia da inovação", segundo Voelpel, Leibold e Eckhoff (2006), poderá ocasionar cinco categorias de problemas, já que o BSC apresenta limitações significativas para lidar com a nova economia, por estar em constante transformação em um ambiente corporativo integrado, conforme demonstra-se no Quadro 2, a seguir.

Quadro 2 - Descrição das cinco categorias de problemas

\begin{tabular}{|c|l|}
\hline Categoria & \multicolumn{1}{c|}{ Descrição } \\
\hline 1 & $\begin{array}{l}\text { O fato de o BSC ser uma ferramenta de medição rígida, sendo os indicadores direcionados a } \\
\text { uma das quatro perspectivas. }\end{array}$ \\
\hline 2 & $\begin{array}{l}\text { O estabelecimento de uma estratégia central direciona o foco para o seu cumprimento, } \\
\text { limitando a realização de outras atividades que possam ir além dos objetivos definidos. }\end{array}$ \\
\hline 3 & $\begin{array}{l}\text { O BSC como um documento interno, que ignora amplamente as necessidades de uma } \\
\text { economia da inovação amplamente interligada. }\end{array}$ \\
\hline 4 & $\begin{array}{l}\text { O BSC trata o conhecimento, aprendizado e crescimento sob a forma tradicional, sendo que } \\
\text { dada uma maior mobilidade dos trabalhadores e a acessibilidade ao capital de risco, o ideal } \\
\text { é que se tenham formas mais abertas de inovação. }\end{array}$ \\
\hline 5 & $\begin{array}{l}\text { A observação de que o BSC é uma mentalidade mecanicista e linear, à medida que os } \\
\text { processos de negócios se tornam mais complexos, tendo em vista a realidade empresarial } \\
\text { atual que envolve atividades interativas e não lineares. }\end{array}$ \\
\hline
\end{tabular}

Fonte: Baseado em Voelpel, Leibold e Eckhoff (2006).

Destaca Othman (2008) que quando o pensamento sobre o BSC é isolado do dinamismo do ambiente externo, este tem a tendência de criar medidas que estão fora de contato com a realidade. As metas estabelecidas não levam em consideração 
as transformações externas e, às vezes, é tratado como fixo. Ele é visto como míope e ignora as atividades e iniciativas que vão além do alvo original. Como tal, mesmo que o BSC seja suposto para ajudar uma organização na implementação da sua estratégia, ele não ajuda a lidar com as mudanças que podem afetar a estratégia das organizações.

Outra dificuldade encontrada na literatura refere-se à implementação do BSC nas empresas. Nesse sentido, Prieto et al. (2006) destacam que elementos, como a falta de comprometimento da alta administração, e discussões não claras e pouco eficientes, são destacadas como fatores críticos no sucesso da implementação do BSC, por não serem práticas usuais das empresas.

\subsection{DEFINIÇÕES SOBRE BIBLIOMETRIA}

A bibliometria caracteriza-se como um "estudo dos aspectos quantitativos da produção, disseminação e uso da informação registrada" (MACIAS-CHAPULA, 1998, p. 134). Para Leal (2005), esse processo de avaliação da ciência não é recente no meio acadêmico e o termo foi usado pela primeira vez por Pritchard, em 1969. A análise bibliométrica permite identificar indicadores, tendências e vieses sobre as publicações científicas. Para Vanti (2002, p. 152), a avaliação de determinado ramo do conhecimento dignifica "o saber quando métodos confiáveis e sistemáticos são utilizados para mostrar à sociedade como tal saber vem-se desenvolvendo e de que forma tem contribuído para resolver os problemas que se apresentam dentro de sua área de abrangência".

Para Cardoso et al. (2005), as revisões são, em geral, feitas por técnicas tradicionais no meio acadêmico, como a análise bibliométrica. Para ele, a análise bibliométrica deve ser acompanhada de pesquisas qualitativas, a fim de que os seus resultados possam ser interpretados em sua abrangência. Os pesquisadores da bibliometria utilizam-se de técnicas para desenvolver seus estudos. Entre essas técnicas, destaca-se a Lei de Lotka, definida por Vanti (2002) como a medição da

produtividade dos autores mediante um modelo de distribuição de tamanho e frequência dos diversos autores em um conjunto de documentos. 
Alguns estudos dessa natureza foram desenvolvidos em diferentes áreas no Brasil. Cardoso et al. (2005) desenvolveu um estudo bibliométrico sobre as publicações científicas, em contabilidade no período entre 1990 e 2003, nas revistas nacionais classificadas com conceito "A" pela Capes. Braga, Stefanello e Gomes (2008) estudaram as publicações sobre o Balanced Scorecard no ENANPAD, no período de 1997 a 2007.

Dias (2007) mapeou as técnicas e os métodos de Avaliação de Sistemas Estratégicos de Informação, no período entre 1985 a 2005, e teve como objetivo esboçar as características, as forças e as variáveis que regem os seus mecanismos, o delineamento histórico e as tendências metodológicas, fazendo o levantamento de artigos publicados nos principais periódicos internacionais sobre "Pesquisas e Avaliações em Sistemas Estratégicos de Informação". Leal, Oliveira e Soluri (2003) desenvolveram um estudo sobre a área de finanças nas publicações de várias revistas, entre elas a Revista de Administração Contemporânea e a Revista de Administração de empresas, no período de 1974 a 2001.

\section{METODOLOGIA}

Para Gil (2008), método é o caminho para se chegar a determinado fim ou objetivo. Métodos científicos são o conjunto de procedimentos intelectuais e técnicos para se chegar a determinado resultado, ou seja, ao conhecimento. Nesta seção, serão abordados aspectos referentes à metodologia de pesquisa utilizada para a elaboração deste estudo.

\subsection{CLASSIFICAÇÃO DA METODOLOGIA}

Quanto aos fins, esta pesquisa pode ser classificada como descritiva. Vergara (2000) esclarece que a pesquisa descritiva tem como objetivo expor características de determinado fenômeno. Quanto ao método, foi utilizada a pesquisa bibliográfica, tendo como instrumentos de coleta os documentos disponibilizados nas bases de dados da SciELO Brasil e da BDTD. 
Já no que se refere à abordagem do problema, este se classifica como quantitativo, visto que foram levantados estudos sobre o tema em questão. Quanto à estratégia, a pesquisa é classificada como descritiva, visto que descreve as características das publicações sob estudo. Como são analisadas as publicações científicas ao longo do tempo, o estudo é classificado como longitudinal (GIL, 2008).

\subsection{COLETA E ANÁLISE DOS DADOS}

A coleta de dados se deu em duas etapas, a partir da base eletrônica de dados SciELO Brasil e da BDTD. Na primeira etapa, foram feitos os seguintes procedimentos:

a) Na base de dados SciELO Brasil, no mês de dezembro de 2011, foi selecionado na seção Periódicos a "Lista por assunto", após "Ciências Sociais Aplicadas". Na sequência, foi selecionado o primeiro periódico disponível.

b) Após selecionar o primeiro periódico disponível, foi feita a pesquisa, utilizando como parâmetros de busca o termo "Balanced Scorecard" ou "BSC", simultaneamente, em todos os níveis e em toda a coleção.

c) Como resultado da pesquisa, foram encontrados 31 artigos, sendo que desses, apenas 9 não se referem ao tema e foram excluídos das análises. Destaca-se que nesta etapa não foi estipulado um período de tempo e que os artigos encontrados corresponderam a todos os disponíveis na base de dados desde a primeira publicação que ocorreu em 2003.

Os artigos encontrados na base de dados da SciELO Brasil foram analisados quantitativamente, com o objetivo de apresentar e analisar o perfil das publicações científicas sobre o tema. Dessa forma, foi necessário identificar o que foi pesquisado sobre o tema (objetivo da pesquisa), os autores e os seus vínculos institucionais e os meios de investigação utilizados pelos pesquisadores. Procurou-se, também, definir a quantidade de autores por artigo, a sua localização geográfica, o ano da publicação, as revistas que publicaram, bem como sua classificação Qualis da Capes. Para a coleta e 
análise dos artigos, foi estruturado um roteiro cujos dados foram armazenados em planilhas do Excel. O roteiro seguiu a sequência apresentada no Quadro 3.

Quadro 3 - Roteiro para coleta de dados na SciELO Brasil

\begin{tabular}{|c|c|}
\hline Sequência & Descrição \\
\hline 1. Autores & $\begin{array}{l}\text { Foi identificado cada um dos autores, principais e secundários dos artigos, de } \\
\text { acordo com o proposto por Alvarado (2002), sendo atribuído o mesmo valor } \\
\text { para cada um. }\end{array}$ \\
\hline $\begin{array}{l}\text { 2. Quantidade de } \\
\text { autores por artigo }\end{array}$ & Foi identificada a quantidade de autores por artigo. \\
\hline $\begin{array}{l}\text { 3. Vínculo institucional } \\
\text { dos autores }\end{array}$ & $\begin{array}{l}\text { Foi identificado o vínculo institucional de cada um dos autores na data das } \\
\text { publicações. }\end{array}$ \\
\hline $\begin{array}{l}\text { 4. Localização } \\
\text { geográfica dos autores }\end{array}$ & $\begin{array}{l}\text { Após vincular os autores às instituições de ensino, foi identificada a localização } \\
\text { geográfica de cada instituição. }\end{array}$ \\
\hline 5. Revista & $\begin{array}{l}\text { Foi identificada cada uma das revistas que publicaram e que disponibilizaram } \\
\text { os artigos na base da SciELO Brasil. }\end{array}$ \\
\hline 6. Ano de publicação & Foi identificado o ano de publicação de cada um dos periódicos. \\
\hline 7. Objetivo da pesquisa & $\begin{array}{l}\text { Foram analisados os resumos de cada um dos artigos para identificar } \\
\text { características similares entre as pesquisas. }\end{array}$ \\
\hline $\begin{array}{l}\text { 8. Os meios de } \\
\text { investigação }\end{array}$ & $\begin{array}{l}\text { Foram verificados no resumo ou então na seção metodologia, os meios de } \\
\text { investigação utilizados. Após estes foram classificados conforme o proposto } \\
\text { por Vergara (2000) e Gil (2008) em: (a) Levantamento; (b) Pesquisa de } \\
\text { Laboratório; (c) Documental; (d) Bibliográfica; (e) Experimental; (f) Ex post } \\
\text { facto; (g) Participante; (h) Pesquisa ação, e (i) Estudo de caso. }\end{array}$ \\
\hline $\begin{array}{l}\text { 9. Classificação Qualis } \\
\text { Capes }\end{array}$ & $\begin{array}{l}\text { Foi identificada a classificação Qualis de cada um dos periódicos, através de } \\
\text { consulta no site da Qualis Capes, para isso foi utilizado o número ISSN de cada } \\
\text { periódico. }\end{array}$ \\
\hline
\end{tabular}

Fonte: Elaborado pelos autores, (2012).

Na segunda etapa da pesquisa, foram feitos os seguintes procedimentos:

a) Na Biblioteca Digital Brasileira de Teses e Dissertações (BDTD), no mês de junho de 2012, foi selecionado o campo "procura básica". Nesse campo, foram digitadas as palavras "Balanced Scorecard" e realizada a pesquisa.

b) Como resultado da pesquisa, foram encontrados 218 documentos, divididos em teses e dissertações.

Os trabalhos encontrados na BDTD foram analisados quantitativamente. Primeiramente, foram identificados o vínculo institucional dos autores e a localização geográfica das instituições. Após foi tabulados o ano de defesa dos trabalhos e o grau (mestre ou doutor), procurou-se, também, evidenciar os objetivos dos estudos e os meios de investigação utilizados pelos pesquisadores. 
Para a coleta e análise das teses e dissertações, foi estruturado um roteiro, cujos dados foram armazenados em planilhas do Excel, seguindo a sequência apresentada no Quadro 4.

Quadro 4 - Roteiro para coleta dos dados na BDTD

\begin{tabular}{|l|l|}
\hline \multicolumn{1}{|c|}{ Sequência } & \multicolumn{1}{c|}{ Descrição } \\
\hline $\begin{array}{l}\text { 1. Vínculo institucional } \\
\text { dos autores }\end{array}$ & No site da BDTD, foi identificado o vínculo institucional de cada um dos autores. \\
\hline $\begin{array}{l}\text { 2. Localização geográfica } \\
\text { dos autores }\end{array}$ & $\begin{array}{l}\text { Após vincular os autores às instituições de ensino, foi identificada a localização } \\
\text { geográfica de cada instituição. }\end{array}$ \\
\hline 3. Ano de defesa & No site da BDTD, foi identificado o ano de defesa de cada um dos trabalhos. \\
\hline $\begin{array}{l}\text { 4. Identificação do Grau } \\
\text { dos Trabalhos }\end{array}$ & $\begin{array}{l}\text { No site da BDTD, foram identificados os trabalhos de acordo com o seu grau em } \\
\text { mestre (dissertação) e doutor (teses). }\end{array}$ \\
\hline 5. Análise dos objetivos & $\begin{array}{l}\text { Foi identificado e tabulado cada um dos objetivos gerais das teses e dissertações, de } \\
\text { acordo com a proposta de cada estudo. }\end{array}$ \\
\hline $\begin{array}{l}\text { 6. Os meios de } \\
\text { investigação }\end{array}$ & $\begin{array}{l}\text { Foi identificada a classificação dos meios de investigação utilizados na elaboração } \\
\text { das pesquisas. Após eles, foram classificados conforme o proposto por Vergara } \\
\text { (2000) e Gil (2008) em: a) Levantamento; b) Pesquisa de Laboratório; c) Documental; } \\
\text { d) Bibliográfica; e) Experimental; f) Ex post facto; g) Participante; h) Pesquisa ação; i) } \\
\text { e Estudo de caso. Destaca-se, também, que os autores das teses e dissertações ao, } \\
\text { por exemplo, classificar a metodologia em Pesquisa Bibliográfica e Estudo de Caso, } \\
\text { foram classificados como Estudo de Caso (isso aconteceu por ser entendido que a } \\
\text { Pesquisa Bibliográfica faz parte de todos os trabalhos). }\end{array}$ \\
\hline
\end{tabular}

Fonte: Elaborado pelos autores, (2012).

Como limitação da pesquisa assume-se que a amostragem, por ser intencional e não probabilística, dificulta o caráter de inferência da pesquisa para outras bases de dados. Na análise dos objetivos, pode haver subjetividade por parte dos autores na identificação e classificação das características semelhantes. Contudo, os dados serviram para traçar o perfil da produção científica brasileira disponibilizada na base de dados da SciELO Brasil e BDTD.

\section{APRESENTAÇÃO E DISCUSSÃO DOS RESULTADOS}

O objetivo desta seção é apresentar os dados coletados e discuti-los, sempre direcionando o trabalho de modo a demonstrar o perfil da produção científica sobre o tema, disponíveis na base de dados SciELO Brasil e da BDTD.

\subsection{PERFIL DAS PUBLICAÇÕES NA BASE DE DADOS DA ScIELO BRASIL}




\subsubsection{Aspectos pesquisados sobre o Balanced Scorecard (objetivo das pesquisas)}

Os artigos pesquisados na base de dados SciELO Brasil sobre o Balanced Scorecard indicam uma grande variedade de objetivos. Destaca-se, no entanto, que alguns deles, intrinsecamente, contêm características semelhantes. Na Tabela 1, por exemplo, apresenta-se um resumo das características dos objetivos. Observa-se que cinco artigos tratam de estudos sobre os sistemas de avaliação de desempenho organizacionais. Outros cinco comparam o BSC com outros modelos ou metodologias. Quatro deles propõem um modelo de avaliação de desempenho com base no BSC ou, então, uma integração do BSC com outras metodologias. Três deles relacionam os estudos do BSC com a estratégia empresarial.

Tabela 1 - Objetivos dos estudos sobre BSC disponíveis na base SciELO Brasil

\begin{tabular}{lcc}
\multicolumn{1}{c}{ Características dos trabalhos } & Quantidade & \% \\
\hline Estudos sobre os sistemas de avaliação de desempenho organizacionais & 5 & 22,73 \\
Comparação do BSC com outros modelos ou metodologias & 5 & 22,73 \\
Proposta de modelo com base no BSC ou proposta de integração com outros & 4 & 18,18 \\
métodos & 3 & 13,64 \\
Trabalhos que tratavam sobre a estratégia empresarial & 3 & 13,64 \\
BSC na área pública ou terceiro setor & 2 & 9,09 \\
Trabalhos voltados para a área agrícola ou agropecuária & $\mathbf{2 2}$ & $\mathbf{1 0 0 , 0 0}$
\end{tabular}

Fonte: Elaborado pelos autores, baseado na pesquisa bibliográfica, (2012).

Outro aspecto interessante demonstrado na Tabela 1 é que 3 artigos apresentam-se voltados para a área pública e do terceiro setor, sendo que outros dois se referem a trabalhos voltados para a área agropecuária.

\subsubsection{Autores das publicações sobre Balanced Scorecard e o seu vínculo institucional}

O estudo proporcionou identificar os autores que estudaram sobre o tema e a quantidade de vezes que cada um publicou. No Tabela 2, apresenta-se a lista desses autores, demonstrando um total de 60 autores que publicaram sobre o BSC nos periódicos disponíveis na base de dados SciElo Brasil. Entre os 60, apenas sete autores publicaram mais de uma vez, sendo que nenhum dos autores publicou mais de dois artigos sobre o tema. Ou seja, a maioria dos autores publicaram apenas uma vez sobre 
o tema, na base de dados SciELO Brasil. Para Cardoso et al. (2005), esse fato demonstra falta de continuidade nas pesquisas ou então falta de continuidade nas publicações científicas por parte dos pesquisadores.

Tabela 2 - Autores que publicaram sobre o BSC na base de dados da SciELO Brasil

\begin{tabular}{|c|c|c|c|c|c|}
\hline Nome & No/A & Nome & No/A & Nome & No/A \\
\hline FRANKLIN, Marcos A. & 2 & FIRMINO, Paulo R. A. & 1 & ORTH, Dora M. & 1 \\
\hline GARDESANI, Roberto. & 2 & FLEURY, Maria T. L. & 1 & PELOIA, Paulo R. & 1 \\
\hline $\begin{array}{l}\text { LAURINDO, Fernando J. } \\
\text { B. }\end{array}$ & 2 & FONSECA, Marcus & 1 & PEREIRA, Carolina Guarçoni & 1 \\
\hline MIYABARA, Walter & 2 & FREZATTI, Fábio & 1 & PEREIRA, Fábio L. A. & 1 \\
\hline PONTE, Vera & 2 & GALAS, Eduardo S. & 1 & PEREIRA, Luis F. P. & 1 \\
\hline POPADIUK, Silvio & 2 & GOMES, Ricardo C. & 1 & PRIETO, Vanderli C. & 1 \\
\hline SPINOLA, Mauro M. & 2 & HIKAGE, Oswaldo K. & 1 & QUELHAS, Oswaldo L. G. & 1 \\
\hline ASATO, Regina & 1 & JUNQUEIRA, Emanuel. & 1 & RAFAELI, Leonardo & 1 \\
\hline ALMADA, Valéria Ferreira & 1 & KIMURA, Herbert & 1 & RELVAS, Tania R. S. & 1 \\
\hline BRANDÃO, Hugo Pena & 1 & LIDDLE, Joyce. & 1 & ROSADO, Adriano G. & 1 \\
\hline CARBONE, Pedro P. & 1 & LIMA, Andréa C. C. & 1 & ROSSETTO, Adriana M. & 1 \\
\hline CARVALHO, Marly M. & 1 & LOBATO, José F. P. L. & 1 & ROSSETTO, Carlos R. & 1 \\
\hline CAVALCANTI, Arlei A. & 1 & MARQUES, Fernanda & 1 & RUAS, Edgar Bertini. & 1 \\
\hline CORDEIRO, João S. & 1 & MEDEIROS, Raffaela M. & 1 & SILVA, Walter H. de F. & 1 \\
\hline COSTA, Helder V. & 1 & MILAN, Marcos. & 1 & $\begin{array}{l}\text { SOARES, T. Diana L. V. A. de } \\
\text { Macedo. }\end{array}$ & 1 \\
\hline COSTA, Ivanir & 1 & MILLS, John & 1 & SOUZA, Ricardo G. & 1 \\
\hline DIETSCHI, Daniel A. & 1 & MULLER, Cláudio J. & 1 & SUEN, Alberto S. & 1 \\
\hline DROGUETT, Enrique A. L. & 1 & NASCIMENTO, Auster M. & 1 & TERRA, Pedro B. & 1 \\
\hline FERNANDES, Bruno H. R. & 1 & OLIVEIRA, Lucas R. & 1 & VILLAS, Marcos & 1 \\
\hline FERREIRA, Ricardo J. & 1 & OLIVEIRA, Paulo E. L. & 1 & ZIMMER, Marco Vinício & 1 \\
\hline
\end{tabular}

Fonte: Elaborado pelos autores, baseado na pesquisa bibliográfica, (2012).

A pesquisa revelou, também, a quantidade de autores por artigo. No Gráfico 1, é demonstrado que dois autores por artigo é a combinação que mais se repete nas publicações, com 36,36\% dos artigos publicados. Em segundo lugar aparecem três autores por artigo, com $27,27 \%$ dos artigos publicados, e em terceiro, quatro autores por artigo, com $22,73 \%$. 
Gráfico 1 - Relação entre o número de autores e o número de artigos

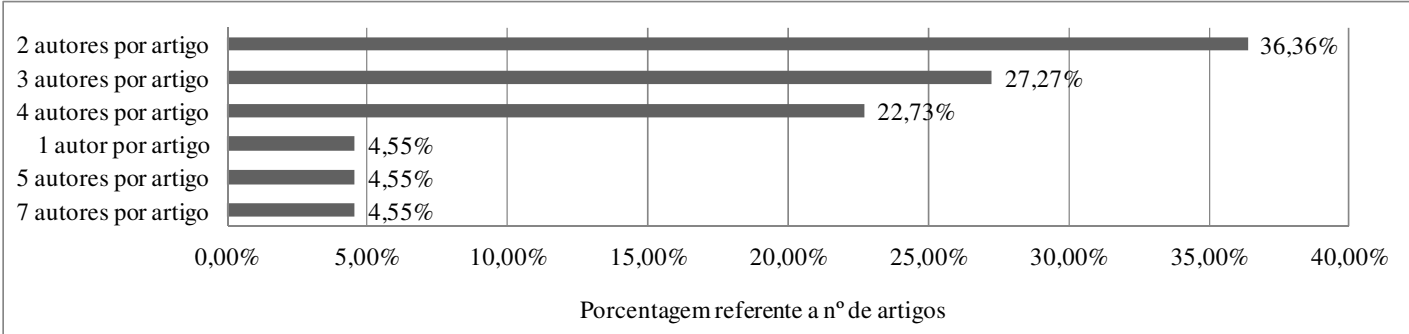

Fonte: Elaborado pelos autores, baseado na pesquisa bibliográfica, (2012).

Nesta pesquisa, foi possível também identificar o vínculo institucional de cada autor, na data de publicação dos artigos. Na Tabela 3, Erro! Fonte de referência não encontrada.apresenta-se o vínculo institucional dos autores. Entre os resultados mais significativos sobre o vínculo institucional dos autores evidenciados na Tabela 3, destaca-se a Escola Politécnica da USP, que corresponde a 11,48\%. Na sequência, apresenta-se, com 8,20\% dos artigos publicados, a Universidade Presbiteriana Mackenzie, assim como a UFRGS e a UNIP. Com 6,56 \%, tem-se a Universidade de Fortaleza, e a UFF.

Tabela 3 -Vínculo institucional de cada autor

\begin{tabular}{lcc}
\hline \multicolumn{1}{c}{ Vínculo institucional } & No/A & $\%$ \\
\hline Escola Politécnica da USP & 7 & 11,48 \\
Universidade Federal do Rio Grande do Sul - UFRGS & 5,20 \\
Universidade Presbiteriana Mackenzie & 5 & 8,20 \\
Universidade Paulista - UNIP & 5 & 8,20 \\
Universidade de Fortaleza & 4 & 6,56 \\
Universidade Federal Fluminense - UFF & 4 \\
Universidade de Brasília - UnB & 3,56 \\
Universidade Federal de Pernambuco - UFPE & 4,92 \\
Faculdade de Economia, Administração e Contabilidade, Universidade de São Paulo - FEA - USP & 3 \\
Escola de Negócios da PUC-Rio - IAG/PUC-Rio & 4,92 \\
Universidade do Vale do Rio dos Sinos - UNISINOS & 2 \\
Universidade do Vale do Itajaí - Univali & 2,92 \\
Escola Superior de Agricultura "Luiz de Queiroz" & 3,28 \\
Fundação Getulio Vargas - FGV-EAESP & 2 \\
Fundação Getulio Vargas - Brasília & 3,28 \\
Universidade Federal do Espírito Santo & 3,28 \\
Universidade Federal de Viçosa & 3,28 \\
Universidade Federal Rural de Pernambuco - UFRPE & 2 \\
Centro Universitário Positivo & 3,28 \\
Gerente de TI da Reduc/Petrobras & 1 & 1,64 \\
& 1 & 1,64 \\
& 1,64
\end{tabular}


Tabela 3 - Vínculo institucional de cada autor (conclusão)

\begin{tabular}{lccc} 
& \multicolumn{1}{c}{ Vínculo institucional } & No/A & $\%$ \\
\hline Universidade Federal do Rio de Janeiro - UFRJ & 1 & 1,64 \\
Universidade de Santa Catarina - UFSC & 1 & 1,64 \\
Pontifícia Universidade Católica de São Paulo - PUC-São Paulo & 1 & 1,64 \\
Universidade Federal de São Carlos & 1 & 1,64 \\
Nottingham Business School & 1 & 1,64 \\
University of Cambridge & 1 & 1,64 \\
\hline Total & $\mathbf{6 1}$ & $\mathbf{1 0 0 , 0 0}$ \\
\hline
\end{tabular}

Fonte: Elaborado pelos autores, baseado na pesquisa bibliográfica, (2012).

Fato importante, e que merece atenção, é a questão de que ao somar os percentuais dessas 6 instituições, tem-se o total de 49,18\% das publicações, ou seja, quase a metade dos autores possui vínculo institucional com uma das 6 primeiras Universidades citadas anteriormente, ficando as outras 20 universidades com os outros 50,82\%. Isso demonstra certo domínio das publicações nessa base de dados por parte dessas 6 universidades.

Ao vincular os autores às instituições de ensino superior e após vincular as instituições à sua respectiva localização geográfica, foi possível vincular geograficamente os autores. No Gráfico 2, apresenta-se a distribuição geográfica da autoria das publicações.

Gráfico 2 - Localização geográfica dos autores

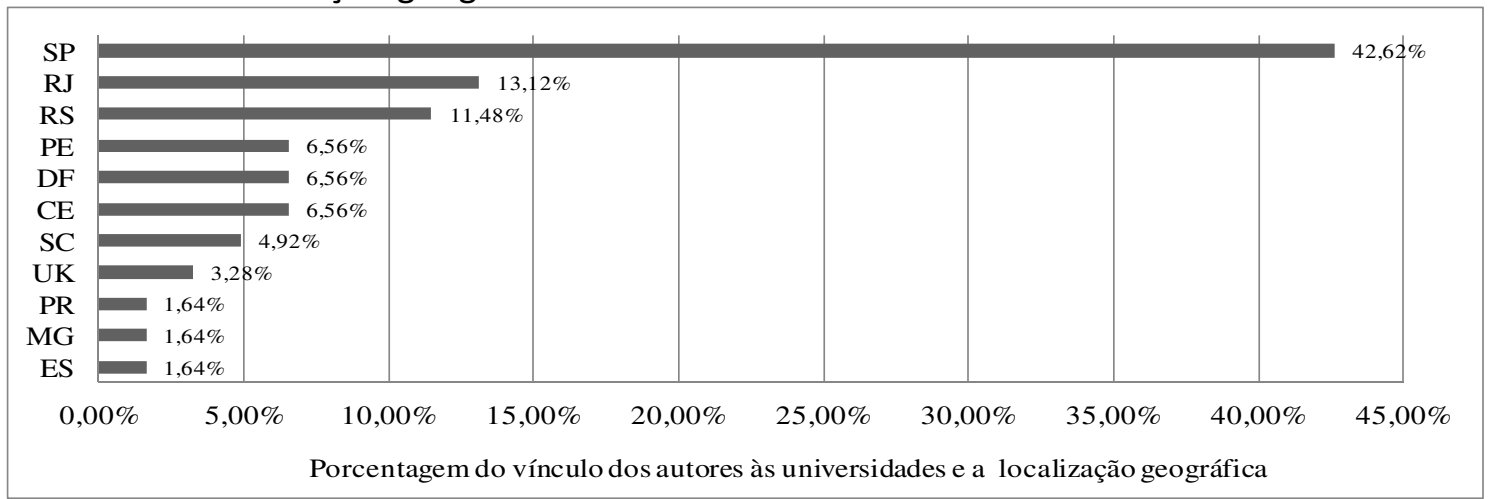

Fonte: Elaborado pelos autores, baseado na pesquisa bibliográfica, 2012. 


\subsubsection{Revistas e suas classificações Qualis Capes e o ano de publicação}

Os periódicos que publicaram sobre o BSC e disponibilizaram os artigos na base de dados SciELO Brasil, encontram-se demonstrados no Quadro 5. Destaca-se que a Classificação Qualis de Periódicos, executado pela Capes, anualmente, varia de A1, o mais elevado, para os níveis A2, B1, B2, B3, B4, B5, até C, com peso zero (CAPES, 2012).

Quadro 5-Perfil das revistas

\begin{tabular}{|l|c|c|}
\hline \multicolumn{1}{|c|}{ Revistas } & Classificação Capes & No de artigos publicados \\
\hline Gestão e Produção & $\mathrm{A} 2$ & 5 \\
\hline Revista Produção & $\mathrm{B} 1$ & 4 \\
\hline Revista de Administração Pública-RAP & $\mathrm{A} 2$ & 3 \\
\hline Revista de Contabilidade e Finanças & $\mathrm{A} 2$ & 3 \\
\hline RAE-eletrônica & $\mathrm{A} 2$ & 2 \\
\hline Revista de administração de empresas - RAE & $\mathrm{A} 2$ & 2 \\
\hline Revista Brasileira de Zootecnia & $\mathrm{B} 1$ & 1 \\
\hline BAR & $\mathrm{A} 2$ & 1 \\
\hline Engenharia Agrícola & $\mathrm{A} 2$ & 1 \\
\hline
\end{tabular}

Fonte: Elaborado pelos autores, baseado na pesquisa bibliográfica, (2012).

Observa-se, nesse quadro, que os periódicos apresentam boa classificação Qualis Capes. A análise refere-se à Classificação Qualis Capes (atualizada em 2012), correspondente à área de avaliação em Administração, Ciências Contábeis e Turismo. Os resultados evidenciados demonstram que 17 artigos foram publicados em revistas que possuem Classificação A2 pela Capes. Desses, a revista "Gestão e Produção" é a que mais apresenta artigos publicados (5), seguida pelas Revistas de Administração Pública e Contabilidade e Finanças.

Por meio da pesquisa, foi possível, também, evidenciar o ano em que aconteceram as publicações. O Gráfico 3, por exemplo demonstra que as publicações nas revistas começaram em 2003 e, a partir desse ano, todos os anos subsequentes tiveram pelo menos uma publicação sobre o BSC. 
Gráfico 3 - Artigos publicados por ano

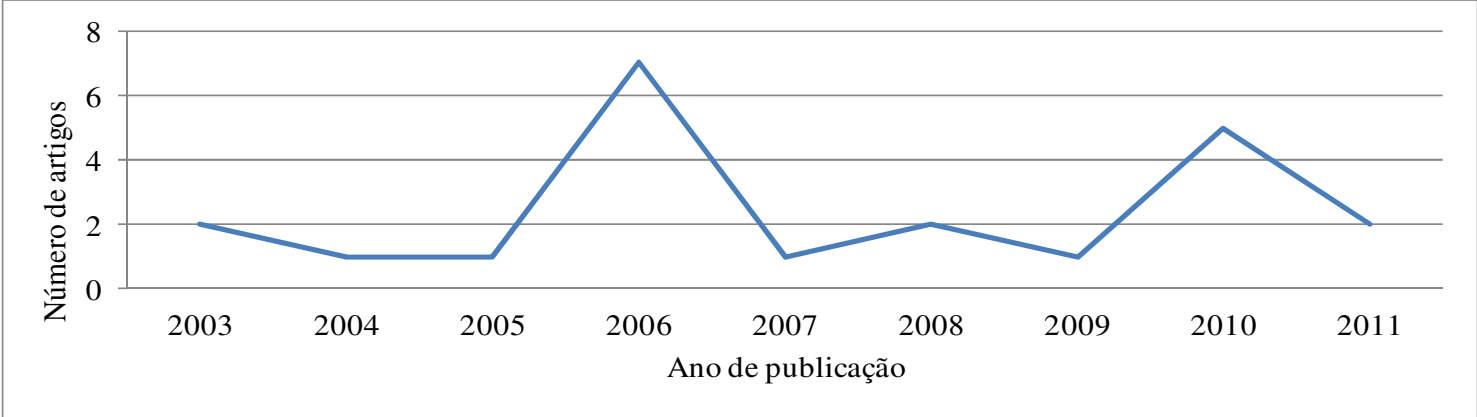

Fonte: Elaborado pelos autores, baseado na pesquisa bibliográfica, (2012).

Tendo em vista que a primeira publicação feita sobre o BSC aconteceu em 1992 por Kaplan e Norton, e que apenas 11 anos depois (2003) é que se teve a primeira publicação disponível na Base de dados da SciELO Brasil, pode-se dizer que as publicações são ainda recentes. Braga, Stefanello e Gomes (2008), em sua pesquisa, também declaram que os estudos sobre o BSC são recentes. Neste estudo desenvolvido pelos autores, as publicações começaram no ano de 2000 e se intensificaram entre os anos de 2004 e 2005.

O Gráfico 3 demonstra, ainda, que dentre os anos que mais tiveram publicações, destaca-se o ano de 2006 e o de 2010, que tiveram, respectivamente, 7 e 5 publicações. Os anos de 2004, 2005, 2007 e 2009 foram os anos que tiveram apenas uma publicação. A média anual de publicações entre 2003 e 2011 é de 2,44 artigos por ano, abaixo da média encontrada por Braga, Stefanello e Gomes (2008), onde, em seu estudo, ficou em 3,87 a média de publicações entre os anos de 2000 e 2007.

\subsubsection{Os meios de investigação utilizados pelos pesquisadores}

Os meios de investigação foram identificados por meio de análises feitas nos resumos, ou então na seção de metodologia de cada artigo. Após essas análises os métodos de pesquisa foram classificados conforme o proposto por Vergara (2000) e Gil (2008) em: a) Levantamento; b) Pesquisa de Laboratório; c) Documental; d) Bibliográfica; e) Experimental; f) Ex post facto; g) Participante; h) Pesquisa ação; e i) Estudo de caso. No Gráfico 4, apresentam-se os resultados dessa classificação. 
Gráfico 4 - Meios de investigação utilizados pelos pesquisadores

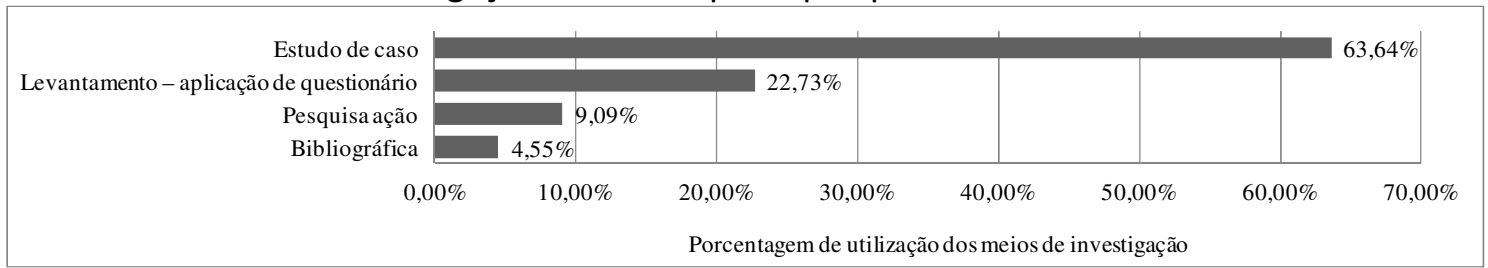

Fonte: Elaborado pelos autores, baseado na pesquisa bibliográfica, (2012).

Observa-se, pelo

Gráfico 4, que o estudo de caso com $63,64 \%$ foi o método mais utilizado pelos pesquisadores. O segundo método mais utilizado pelos pesquisadores é o levantamento, com $22,73 \%$. Esse método se concretiza com o levantamento de dados, por meio da aplicação de survey ou questionários. Na sequência, aparece a pesquisa ação com cerca de $9 \%$, e, por último, a pesquisa bibliográfica.

\subsection{PERFIL NA BASE DE DADOS DA BIBLIOTECA DIGITAL BRASILEIRA DE TESES E DISSERTAÇÕES (BDTD)}

\subsubsection{Vínculo Institucional dos autores e a localização geográfica das Instituições}

Por meio da pesquisa efetuada no site da Biblioteca Digital Brasileira de Teses e Dissertações, foi possível identificar o vínculo institucional de cada um dos autores. Como resultado, tem-se um total de 37 instituições, que disponibilizaram na base de dados da BDTD, somando-se 218 trabalhos. Os resultados serão apresentados na Tabela 4.

Observa-se na Tabela 4 que a instituição que mais disponibilizou trabalhos sobre o BSC foi a Universidade Federal do Rio Grande do Sul, com 22,48\%, seguida pela Universidade de São Paulo (8,72\%), pela Universidade Federal de Pernambuco $(8,72 \%)$, pela Universidade Federal de Campinas (6,42\%) e pela Universidade Federal do Rio Grande do Norte (5,05\%). A soma das publicações dessas 6 instituições representa um total de 51,39\%, ou seja, 51,39\% dos trabalhos são de 6 instituições, enquanto que os outros $48,61 \%$ são de 31 instituições. 
Tabela 4 - Vínculo Institucional dos Autores

\begin{tabular}{|c|c|c|}
\hline Vínculo institucional & №. de trabalhos & $\%$ \\
\hline 1 - Universidade Federal do Rio Grande do Sul & 49 & 22,48 \\
\hline 2 - Universidade de São Paulo & 19 & 8,72 \\
\hline 3 - Universidade Federal de Pernambuco & 19 & 8,72 \\
\hline 4 - Universidade Estadual de Campinas & 14 & 6,42 \\
\hline 5 - Universidade Federal do Rio Grande do Norte & 11 & 5,05 \\
\hline 6 - Pontifícia Universidade Católica de São Paulo & 10 & 4,59 \\
\hline 7 - Universidade Federal da Bahia & 9 & 4,13 \\
\hline 8 - Faculdade Escola de Comércio Álvares Penteado & 7 & 3,21 \\
\hline 9 - Universidade Federal de Santa Maria & 7 & 3,21 \\
\hline 10 - Pontifícia Universidade Católica do Rio de Janeiro & 5 & 2,29 \\
\hline 11 - Pontifícia Universidade Católica do Rio Grande do Sul & 5 & 2,29 \\
\hline 12 - Universidade do Vale do Rio do Sinos & 5 & 2,29 \\
\hline 13 - Universidade Federal de São Carlos & 5 & 2,29 \\
\hline 14 - Universidade Federal do Ceará & 5 & 2,29 \\
\hline 15 - Universidade Federal Rural do Rio de Janeiro & 5 & 2,29 \\
\hline 16 - Universidade Regional de Blumenau & 5 & 2,29 \\
\hline 17 - Universidade Católica de Brasília & 4 & 1,83 \\
\hline 18 - Universidade Federal de Santa Catarina & 4 & 1,83 \\
\hline 19 - Instituto Tecnológico de Aeronáutica & 3 & 1,38 \\
\hline 20 - Pontifícia Universidade Católica do Paraná & 3 & 1,38 \\
\hline 21 - Universidade de Brasília & 3 & 1,38 \\
\hline 22 - Fundação João Pinheiro & 2 & 0,92 \\
\hline 23 - Universidade de Caxias do Sul & 2 & 0,92 \\
\hline 24 - Universidade Federal de Goiás & 2 & 0,92 \\
\hline 25 - Universidade Federal de Minas Gerais & 2 & 0,92 \\
\hline 26 - Universidade Salvador & 2 & 0,92 \\
\hline 27 - Instituto de Pesquisas Tecnológicas do Estado de São Paulo & 1 & 0,46 \\
\hline 28 - Universidade Anhembi Morumbi & 1 & 0,46 \\
\hline 29 - Universidade Católica de Santos & 1 & 0,46 \\
\hline 30 - Universidade de Fortaleza & 1 & 0,46 \\
\hline 31 - Universidade do Estado do Rio de Janeiro & 1 & 0,46 \\
\hline 32 - Universidade do Vale do Itajaí & 1 & 0,46 \\
\hline 33 - Universidade Estadual do Norte Fluminense Darcy Ribeiro & 1 & 0,46 \\
\hline 34 - Universidade Federal de Lavras & 1 & 0,46 \\
\hline 35 - Universidade Federal de Uberlândia & 1 & 0,46 \\
\hline 36 - Universidade Federal de Viçosa & 1 & 0,46 \\
\hline 37 - Universidade Nove de Julho & 1 & 0,46 \\
\hline Total & 218 & 100,00 \\
\hline
\end{tabular}

Fonte: Elaborado pelos autores, com base na pesquisa bibliográfica, (2012).

Ao vincular as Instituições a sua localização geográfica, foi possível identificar a distribuição geográfica dos trabalhos desenvolvidos. 0

Gráfico 5, por sua vez, evidencia os Estados com maior produção. O Estado do Rio Grande do Sul, por exemplo, aparece em primeiro lugar, com 31,19\%, seguido por São Paulo, com 28,44\%. As Instituições dos Estados de Goiás, Paraná e Ceará são as que menos publicaram na BDTD. Obviamente, esta análise é feita sobre as publicações existentes na base de dados da BDTD, sendo que há instituições de outros 
Estados que não apresentaram nenhum trabalho disponibilizado, como é o caso, por exemplo, de Mato Grosso, Amazonas, Piauí etc.

Gráfico 5 - Localização geográfica das Instituições

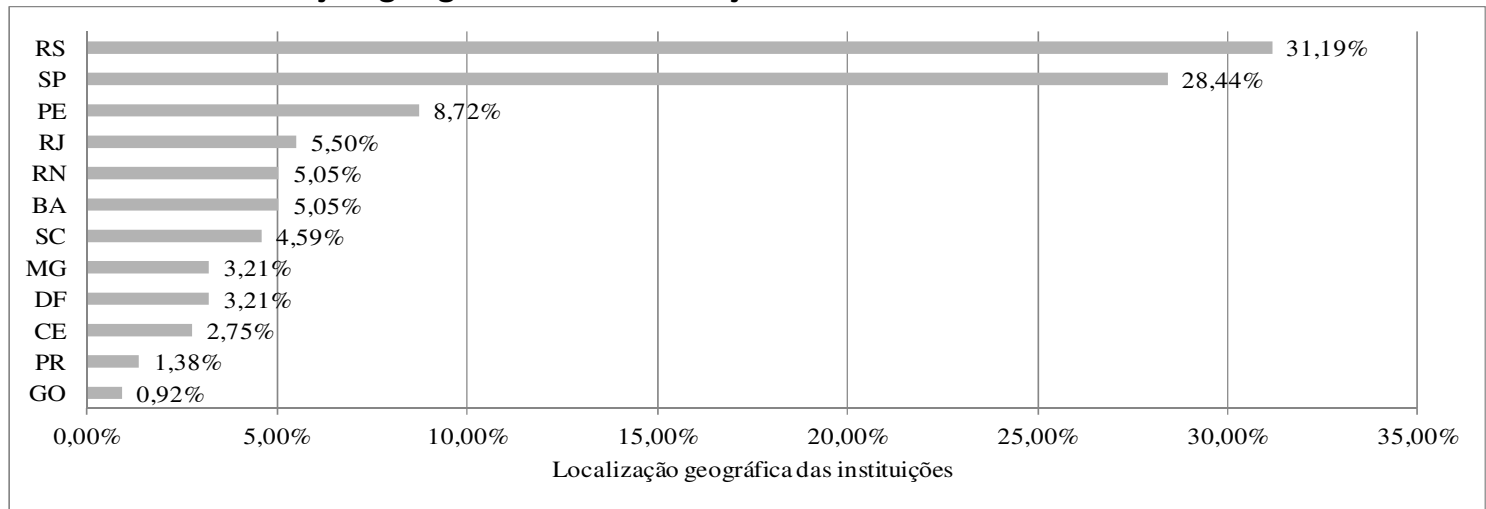

Fonte: Elaborado pelos autores, baseado na pesquisa bibliográfica, (2012).

\subsubsection{Ano de defesa dos trabalhos, grau (teses ou dissertações) e os meios de investigação utilizados pelos pesquisadores}

No site da Biblioteca Digital Brasileira de Teses e Dissertações (BDTD), foi possível identificar a proporção de dissertações e teses que foram disponibilizadas. Do total de 218 trabalhos, 206 são dissertações (94,5\%) e 12 são teses (5,5\%). Foram identificados, também, os anos de defesas dos trabalhos disponibilizados. No Gráfico 6, apresentam-se os resultados. Observa-se que os estudos iniciaram no ano de 2000 com uma tese e foram aumentando até 2008 , atingindo 34 estudos (33 dissertações e 01 tese). Observa-se que a partir do ano de 2008 começou a se ter uma redução dos trabalhos disponibilizados.

Gráfico 6 - Ano de defesa dos trabalhos

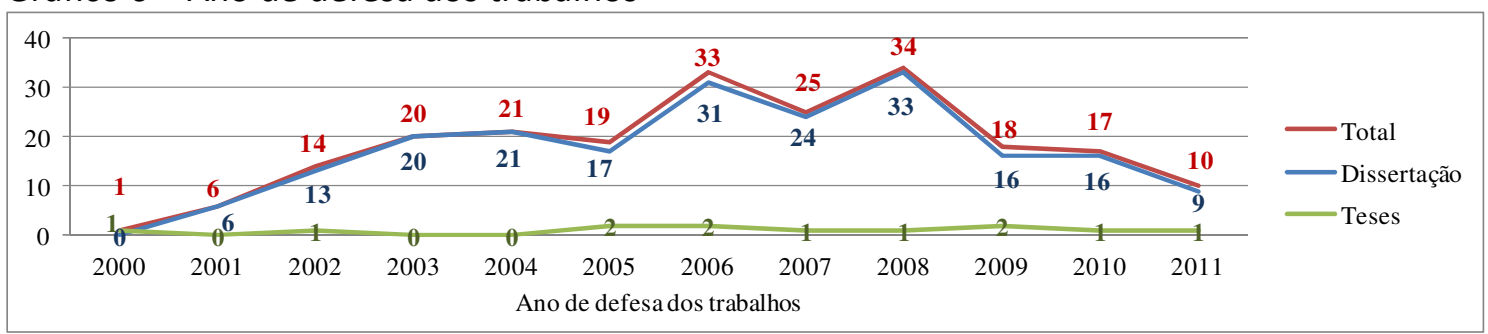

Fonte: Elaborado pelos autores, baseado na pesquisa bibliográfica, (2012). 
Os meios de investigação foram identificados por meio de análises feitas na seção Metodologia das Dissertações e Teses. Destaca-se que, entre os 218 trabalhos disponibilizados, teve-se acesso a somente 174. Ou seja, foi possível acessar 44 trabalhos, seja por problemas nos arquivos ou restrições institucionais das Universidades. Dessa forma, estes 44 foram excluídos da análise.

Após acessar cada um dos trabalhos, foi verificada a classificação que os pesquisadores fizeram. Em seguida, os trabalhos foram distribuídos nos seguintes grupos: a) Levantamento; b) Pesquisa de Laboratório; c) Documental; d) Bibliográfica; e) Experimental; f) Ex post facto; g) Participante; h) Pesquisa ação; e i) Estudo de caso. As classificações efetuadas de forma diferente foram tratadas, nesta pesquisa, como outras. No

Gráfico 7, apresentam-se os resultados dessa classificação.

Gráfico 7 - Meios de investigação utilizados

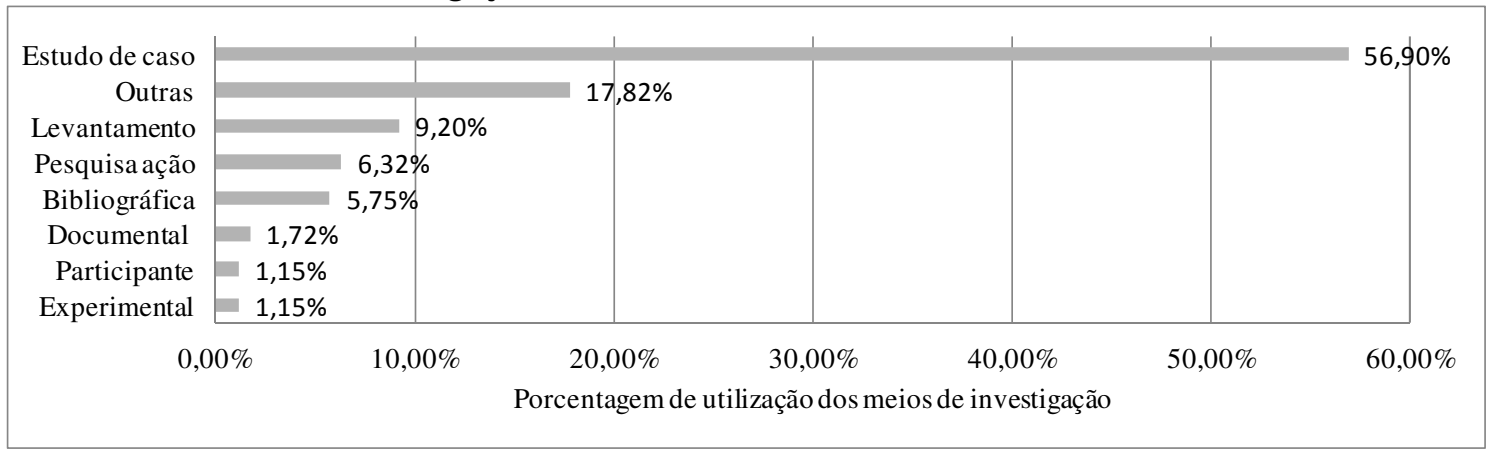

Fonte: Elaborado pelos autores, baseado em pesquisa bibliográfica, (2012).

\section{Observa-se, pelo}

Gráfico 7, que o estudo de caso com $56,09 \%$ foi o método mais utilizado pelos pesquisadores. Em segundo lugar, aparecem as várias outras metodologias utilizadas, com 17,82\%. O levantamento foi utilizado por 9,2\% dos pesquisadores. Entre os menos utilizados, encontram-se a pesquisa experimental (1,15\%), a participante $(1,15 \%)$ e a documental $(1,72 \%)$. 


\subsubsection{Aspectos pesquisados sobre o Balanced Scorecard (objetivos dos trabalhos)}

Ao analisar os objetivos das teses e dissertações disponibilizadas na base de dados da BDTD, não foi possível acessar 44 trabalhos que foram excluídos da análise. Além disso, em 2 dissertações não foi possível identificar com clareza o objetivo geral o que resultou também na exclusão da análise. Os objetivos foram classificados de acordo com as semelhanças que apresentavam. Os resultados são apresentados na Tabela 5.

Observa-se, na Tabela 5, que a característica que mais se repetiu nos estudos desenvolvidos foram as propostas de modelos de avaliação de desempenho com base no BSC, ou então propostas de integração do BSC com outros métodos ou metodologias, com $16,86 \%$. Estudos que tratam sobre a estratégia das empresas aparecem em segundo lugar, com 14,53\%, juntamente com estudos que tratam sobre os sistemas de avaliação de desempenho de forma geral.

Tabela 5 - Características dos objetivos

\begin{tabular}{lrr}
\hline \multicolumn{1}{c}{ Características dos objetivos dos trabalhos } & Quantidade & \% \\
\hline Proposta de modelo com base no BSC ou de integração com outros & 29 & 16,86 \\
métodos & 25 & 14,53 \\
Trabalhos que tratavam sobre a estratégia empresarial & 25 & 14,53 \\
Estudos sobre os sistemas de avaliação de desempenho organizacionais & 24 & 13,95 \\
Aplicação e teoria sobre o BSC & 23 & 13,37 \\
BSC na área pública ou terceiro setor & 11 & 6,40 \\
Trabalhos que tratavam sobre a implantação do BSC & 6 & 3,49 \\
Trabalhos voltados para a área agrícola ou agropecuária & 6 & 3,49 \\
Comparação do BSC com outros modelos ou metodologias & 23 & 13,37 \\
Outros & 172 & 100,0 \\
\hline
\end{tabular}

Fonte: Elaborado pelos autores, com base em pesquisa bibliográfica, (2012).

Outro resultado que chama a atenção são os estudos sobre o BSC, voltados para a área pública ou então para empresas do terceiro setor, que aparecem com 13,37\%. Em menor quantidade, aparecem estudos sobre a metodologia do BSC voltados para a área agrícola ou agropecuária $(3,49 \%)$. 
A análise conjunta das duas bases de dados permite-nos fazer algumas observações. Por exemplo: a Universidade Federal do Rio Grande do Sul foi a instituição que mais disponibilizou trabalhos (teses e dissertações) na BDTD (22,82\%), porém ficou em 20 lugar nas publicações nas revistas que disponibilizam seus artigos na SciELO Brasil (8,20\%). A Universidade de São Paulo ficou em 2ㅇ lugar na BDTD e foi a que mais contribuiu para a publicação nas revistas da SciELO Brasil.

Outro exemplo é a Universidade de Pernambuco, que ficou em 3익 lugar na BDTD, e na SciELO Brasil, aparece em 8o lugar, com 4,92\% dos trabalhos disponibilizados. A Universidade de Campinas ficou em 4 일 lugar na BDTD, com 6,42\% das publicações, sendo que nas revistas da SciELO Brasil, ela não apresentou trabalhos. Caso semelhante aconteceu com a Universidade Federal do Rio Grande do Norte, que na BDTD aparece em 50 lugar, e na SciELO Brasil, não foi identificado nenhum trabalho, ou seja, a produção das Universidades não corresponde na mesma proporção às publicações das revistas na base de dados da SciELO Brasil. Essa discrepância aparece também ao observar a localização geográfica das instituições. Por exemplo, na BDTD, o Estado que aparece em 1일 lugar é o Rio Grande do Sul (31,19\%), em 2으, São Paulo, 3으, Pernambuco. Na SciELO Brasil, o ranking é: São Paulo (42,62\%), Rio de Janeiro $(13,12 \%)$ e Rio Grande do Sul (11,48\%).

Ao analisar conjuntamente os anos das publicações nas duas bases de dados, também é possível identificar outras características. Observa-se que na BDTD, as defesas iniciaram no ano de 2000, e que na SciELO Brasil as publicações começaram apenas em 2003. O ano de 2006 foi o que mais apresentou publicações sobre o tema na SciELO Brasil. Na BDTD, nesse ano, também houve uma boa quantidade de trabalhos defendidos. Tendo em vista que o primeiro trabalho publicado sobre o BSC aconteceu em 1992, com Kaplan e Norton, pode-se inferir que esses ainda são recentes no Brasil.

Ao observar os meios de investigação utilizados pelos pesquisadores, observa-se coerência nos dados levantados. $O$ estudo de caso em ambas as bases de 
dados foi o meio mais utilizado para o levantamento dos dados, seguido pelo levantamento, pesquisa e ação bibliográfica.

Ao analisar as características dos objetivos dos trabalhos disponibilizados em ambas as bases de dados, é possível notar que estas apresentam semelhanças. Por exemplo, a proposta de modelo com base no BSC ou proposta de integração com outros métodos é uma das características que mais aparece, juntamente com os estudos sobre sistemas de avaliação de desempenho e estudos que tratam sobre a estratégia empresarial, ou seja, a filosofia do BSC é incorporada com outros métodos. Sobre esse aspecto, Lima, Cavalcante, e Ponte (2004) defendem que a filosofia do BSC é incorporada com outro método, seja para facilitar o nível de comunicação na empresa, seja para alcançar os objetivos estratégicos.

A revisão bibliográfica demonstra que a proposta inicial do Balanced Scorecard era mais voltada para a mensuração de desempenho e para controle. Mas com o decorrer do tempo, a proposta do BSC muda e este passa a ser utilizado como uma ferramenta para o desdobramento do planejamento estratégico da empresa. Nesse sentido, a análise dos objetivos revela que a estratégia é um dos temas mais relacionados com o $\mathrm{BSC}$ nos estudos disponibilizados em ambas as bases de dados.

Aparecem, também, em ambas as bases, trabalhos voltados para o terceiro setor, para a área pública e também para a área agropecuária. Isso demonstra que os pesquisadores tendem a utilizar da filosofia do Balanced Scorecard não só em empresas com fins lucrativos, mas também na administração pública e nas empresas do terceiro setor, bem como no ramo agropecuário.

\section{CONSIDERAÇÕES FINAIS}

Este artigo procurou identificar como as publicações científicas sobre o BSC tratam o tema no Brasil. Assim, o objetivo foi apresentar e analisar o perfil das publicações científicas brasileiras sobre o sistema de avaliação de desempenho Balanced Scorecard.

Para atender a esse objetivo, foram analisados os trabalhos disponibilizados na base de dados SciELO Brasil e na Biblioteca Digital Brasileira de 
Teses e Dissertações (BDTD). Por meio dessa revisão, buscou-se identificar os objetivos dos estudos publicados, os autores e o vínculo institucional de cada um, os periódicos que publicaram sobre o BSC e sua classificação Qualis Capes, o ano da publicação e a metodologia utilizada pelos pesquisadores. Trata-se de um estudo quantitativo, em que, para o seu desenvolvimento, foram realizadas pesquisas bibliográficas e análise bibliométrica.

A identificação do perfil das publicações científicas sobre o BSC demonstrou que os trabalhos aparecem com uma grande variedade de objetivos voltados para empresas não só com fins lucrativos como também para empresas do terceiro setor, da área pública e para o ramo agropecuário. Os periódicos que publicaram sobre o BSC apresentam boa classificação Qualis Capes. Poucos autores publicaram mais que um artigo (7), sendo que dois autores por artigo é a combinação que mais se repete nas publicações na base SciELO Brasil. A maioria dos trabalhos são de autores vinculados às instituições do Estado do Rio Grande do Sul, São Paulo, Rio de Janeiro e Pernambuco. Esses resultados estão condizentes com o estudo bibliométrico desenvolvido por Braga, Stefanello e Gomes (2008) sobre o BSC. Neste estudo, os autores destacam que 70 dos 73 autores tiveram apenas uma publicação e que os estados que mais contribuíram foram Estado do Rio Grande do Sul, São Paulo, Rio de Janeiro e Pernambuco.

A pesquisa revelou, também, que a produção científica na base de dados da BDTD corresponde a 218 trabalhos disponibilizados entre o ano 2000 e 2011. Na SciELO Brasil, foram disponibilizados 22 trabalhos entre os anos 2003 e 2011. O estudo de caso foi a metodologia mais utilizada pelos pesquisadores, o que revela semelhança com o estudo desenvolvido por Aragão, Forte e Oliveira (2010), que desenvolveram uma análise bibliométrica na área da administração. Nesta pesquisa desenvolvida pelos autores, eles concluíram que o estudo de caso representa $54 \%$ das metodologias de pesquisa utilizada pelos autores.

Em relação às limitações dessa pesquisa, assume-se que a amostragem, por ser intencional e não probabilística, dificulta o caráter de inferência da pesquisa para outras bases de dados. Nesse sentido, são necessários estudos que incluam 
outras bases de dados. Isso ajudará a definir o perfil das publicações sobre o Balanced Scorecard.

Este trabalho não esgota o assunto Balanced Scorecard, mas auxilia a contextualizá-lo em uma perspectiva do perfil das publicações sobre o tema. Uma melhor caracterização das publicações pode auxiliar em pesquisas empíricas que mapeiem a utilização do BSC, sob o ponto de vista organizacional. Como sugestão para novos estudos, instiga-se a descobrir o porquê de se ter mais estudos disponibilizados em determinados Estados e, também, se fatores como financiamento de pesquisa, caráter político, quantidade de população, perspectiva histórica, influenciam na produção científica sobre o tema.

\section{PROFILE OF BRAZILIAN SCIENTIFIC PRODUCTION ABOUT BALANCED SCORECARD}

\section{ABSTRACT}

This study aims to present and analyze the profile of scientific publications on the system performance evaluation Balanced Scorecard (BSC) available in the database SciELO Brazil and the Brazilian Digital Library of Theses and Dissertations (BDTD). This is a quantitative study and its development were carried out literature searches and bibliometric analysis. Through this research identified the objectives of the studies, how much work available in the databases, the institutional affiliation of authors, year of publication or defense of this work, as well as the methodology used by researchers and the scientific production of each State. Specifically in the database of SciELO Brazil was still possible to identify the authors and the journals that published the articles. The study revealed, among other things, that the publications on the BSC, demonstrate a wide variety of purposes and that researchers tend to use the philosophy of the Balanced Scorecard not only for-profit companies, but also in public administration and business third sector and the agricultural industry. Studies on the BSC in Brazil began in 2000. Two authors per article is the combination that is repeated in most publications in the SciELO Brazil. The geographic location states that contributed the most were: Rio Grande do Sul, São Paulo, Rio de Janeiro and Pernambuco. 
Key words: Performance evaluation. Balanced Scorecard. Bibliometrics.

\section{REFERÊNCIAS}

ALVARADO, R. U. A Lei de Lotka na bibliometria brasileira. Ciência da informação, Brasília, v. 31, n. 2, p. 14-20, maio/ago. 2002.

ARAGÃO, L. A.; FORTE, S H. A. C.; V. Visão baseada em recursos e capacidades dinâmicas no contexto brasileiro: a produção e a evolução acadêmica em dez anos de contribuições. Revista Eletrônica de Administração, Porto Alegre, v. 16, p. 127-150, maio/ago, 2010. Disponível em:

<http://www.read.ea.ufrgs.br/edicoes/pdf/artigo_624.pdf>. Acesso em: 20 dez. 2011.

ASSIRI, A.; ZAIRI, M.; EID, R. How to profit from the Balanced Scorecard an implementation roadmap. Emerald Industrial Management and Data Systems, Bingley, v. 106, n. 7, p. 937-952, aug. 2006.

ATKINSON, A A.; BANKER, R. D.; KAPLAN, R. S.; YOUNG, S. M. Contabilidade gerencial. 2. ed. São Paulo: Atlas, 2008.

BANKER, R. D.; CHANG, H.; PIZZINI, M. The judgmental effects of strategy maps in Balanced Scorecard performance evaluations. International Journal of Accounting Information Systems, Amsterdã, v. 12, n. 4, p. 259-279, dez. 2011.

BERTUCCI, J. L. O; HIRSCHHEIMER, E. Sistemas de avaliação de performance em empresas do setor de serviços: o desafio de alinhar estratégias e processos.

Administração em Diálogo, São Paulo, v. 7, n. 1, p. 39-52, jan./abr. 2005.

BRAGA, A. L.; STEFFANELLO, M.; GOMES, C. M. Aplicação Científica da metodologia Balanced Scorecard: um estudo longitudinal. In: XI SEMEAD, 2008, São Paulo. Anais eletrônicos...São Paulo: Faculdade de Economia, Administração e Contabilidade FEAUSP, 2008. Disponível em:

<http://www.ead.fea.usp.br/semead/11semead/resultado/trabalhosPDF/801.pdf>. Acesso em: 07 jan. 2012.

COORDENAÇÃO DE APERFEIÇOAMENTO DE PESSOAL DE NÍVEL SUPERIOR - CAPES. Qualis periódico. Disponível em:

<http://www.capes.gov.br/avaliacao/qualis?format=pdf>. Acesso em: 07 jun. 2012.

CARDOSO, R. L.; NETO, O. R. M.; RICCIO, E. L.; SAKATA, M. C. G. Pesquisa científica em contabilidade entre 1990 e 2003. Revista de Administração de Empresas, São Paulo, v. 45, n. 2, p. 34-45, abr./jun. 2005.

CHAVAN, M. The Balanced Scorecard: a new challenge. Journal of Management Development, Bingley, v. 28, n. 5, p. 393-406, june 2009. 
DIAS, F. S. Avaliação de Sistemas Estratégicos de Informação. Revisão de Métodos e Técnicas. In: XXXI Congresso Nacional de Pós Graduação em Administração ENANPAD, 31, 2007, Rio de Janeiro. Anais... Rio de Janeiro: XXXI Congresso Nacional de Pós Graduação em Administração - ENANPAD, 2007. De 22 a 26 setembro de 2007.

DIEHL, C. A.; CARDOSO, M. F. Divulgação de indicadores de desempenho financeiros e não financeiros por organizações inseridas em ambiente de inovação tecnológica. In: Congresso USP de Controladoria e Contabilidade, 11, 2011. São Paulo. Anais eletrônicos. São Paulo: Faculdade de Economia, Administração e Contabilidade FEAUSP, 2011. Disponível em:

<http://www.congressousp.fipecafi.org/artigos112011/104.pdf>. Acesso em: 07 jan. 2012.

DIETSCHI, D. A.; NASCIMENTO, A. M. Um estudo sobre a aderência do Balanced Scorecard às empresas abertas e fechadas. Revista de contabilidade e finanças, São Paulo, v. 19, n. 46, p. 73-85, jan./abr. 2008.

FREZATTI, F. Orçamento Empresarial. 5. ed. São Paulo: Atlas, 2009.

GASSENFERTH, W.; SOARES, M. A. M. Uma análise da evolução do balanced scorecard como ferramenta de controle de desempenho e sua relação com os indicadores financeiros. Revista de Administração Mackenzie, São Paulo, v. 8, n. 2, p. 162-186, mar./abr., 2007.

GIL, A. C. Métodos e técnicas de pesquisa social. 6. ed. São Paulo: Atlas, 2008.

KAPLAN, R. S.; NORTON, D. P. The Balanced Scorecard: Measures That Drive Performance. Harvard Business Review, Cambridge, v. 70, n. 1, p. 71-79, jan./feb. 1992.

Organização orientada para a estratégia: como as empresas que adotam o Balanced Scorecard prosperam no novo ambiente de negócios. Rio de Janeiro: Campus, 2000.

.Transforming the Balanced Scorecard from Performance Measurement to Strategic Management: Part I. Accounting Horizons, Sarasota, v. 15, n. 1, p. 87-104, mar., 2001.

.Using the Balanced Scorecard as a Strategic Management System. Harvard Business Review, Cambridge, v. 85, n.7/8, p. 150-161, jul./aug. 2007.

LEAL, I. C. Análise de citações da produção científica de uma comunidade: A construção de uma ferramenta e sua aplicação em um acervo de teses e dissertações do PPGCI-UFMG. 2005. 94 f. Dissertação (Mestrado em Ciência da Informação). 
Programa de Pós-Graduação em Ciência da Informação. Universidade Federal de Minas Gerais, Belo Horizonte, MG, 2005.

LEAL, R. P. C.; OLIVEIRA, J; SOLURI, A. F. Perfil da pesquisa em finanças no Brasil. Revista de Administração de Empresas, São Paulo, v. 43, n. 1, p. 91-103, jan./mar., 2003.

LEMOS, R. C. A.; PESSOA, M. N. M.; SANTOS, S. M.; CABRAK, A. C. A.; NASCIMENTO, D. C. Fatores potencializadores e restritivos à implantação do balanced scorecard: um estudo em uma empresa de construção civil do Ceará. Revista Eletrônica de Estratégia \& Negócios, Florianópolis, v. 4, n. 2, p. 3-29, jun./dez. 2011. Disponível em: < https://www.portaldeperiodicos.unisul.br/ojs/index.php/EeN/article/view/623/708>. Acesso em: 11 abr. 2012.

LETZA, S. R. The design and implementation of the balanced business scorecard an analysis of three companies in practice. Business Process Management Journal, Bingley, v. 2, n. 3, p. 54-76, may/june 1996.

LIMA, A. C. C.; CAVALCANTE, A. A.; PONTE, V. Da onda da gestão da qualidade a uma filosofia da qualidade da gestão: balanced scorecard promovendo mudanças. Revista Contabilidade e Finanças, São Paulo, ed. esp., p. 79-94, jun. 2004.

LOPES, A R. U. Os reflexos da implantação do Balanced Scorecard no desempenho organizacional: Estudo de caso da Degrémont Tratamento de Águas Ltda. 2011. 172 f. Dissertação (Mestrado em Ciências Contábeis) Programa de Estudos Pós-Graduação em Ciências Contábeis. Pontifícia Universidade Católica de São Paulo, São Paulo, SP, 2011.

MACIAS-CHAPULA, C. A. O papel da informetria e da cienciometria e sua perspectiva nacional e internacional. Ciência da informação, Brasília, v. 27, n. 2, p. 134-140, maio/ago., 1998.

OTHMAN, R. Enhancing the effectiveness of the balanced scorecard with scenario planning. International Journal of Productivity and Performance Management, Bingley, v. 57, n. 3, p. 259-266, abr. 2008.

PRIETO, V. C.; PEREIRA, F. L. A.; CARVALHO, M. M.; LAURINDO, F. J. B. Fatores críticos na implementação do Balanced Scorecard. Gestão e Produção, São Carlos, v. 13, n. 1, p. 81-92, jan./abr. 2006.

SINK, D. S.; TUTTLE, T. C. Planejamento e medição para performance. Rio de Janeiro: Qualitymark, 1993.

VALMOHAMMADI, C.; SERVATI, A. Performance measurement system implementation using Balanced Scorecard and statistical methods. International Journal of Productivity and Performance Management, Bingley, v. 60, n. 5, p. 493-511, jun. 2011. 
VANTI, N. A. P. Da bibliometria à webometria: uma exploração conceitual dos mecanismos utilizados para medir o registro da informação e a difusão do conhecimento. Revista Ciência da Informação, Brasília, v. 31, n. 2, p. 152-162, maio/ago. 2002.

VERGARA, S. C. Projetos e relatórios de pesquisa em administração. São Paulo: Atlas, 2000.

VILA, M.; COSTA, G.; ROVIRA, X. The creation and use of scorecards in tourism planning: A Spanish example. Tourism Management, Amsterdã, v. 31, n. 2, p. 232-239, abr. 2010.

VOELPEL, S. C.; LEIBOLD, M.; ECKHOFF, R. A. The tyranny of the Balanced Scorecard in the innovation economy. Journal of Intellectual Capital, Bingley v. 7, n. 1, p. 43-60, jan./mar. 2006. 